\title{
Composite tumor with pheochromocytoma and immature neuroblastoma: report of two cases with cytogenetic analysis and discussion of current terminology
}

\author{
${\text { Lily } \operatorname{Tran}^{1} \cdot \text { Carrie Fitzpatrick }}^{1} \cdot$ Susan L. Cohn ${ }^{2} \cdot$ Peter Pytel $^{1}$
}

Received: 13 March 2017 /Revised: 27 July 2017 / Accepted: 21 August 2017 / Published online: 1 September 2017

(C) The Author(s) 2017. This article is an open access publication

\section{Introduction}

Pheochromocytoma, paraganglioma, and neuroblastoma are all derived from sympathetic nervous tissues and can exhibit a spectrum of morphology. The literature includes reports of tumors with morphologic features of both pheochromocytoma and neuroblastoma within the same tumor. The term "composite pheochromocytoma" has been used to describe these tumors as well as pheochromocytomas with other neural crest derivatives, such as malignant peripheral nerve sheath tumor and neuroendocrine carcinoma. "Composite pheochromocytoma" is rare, and there is a paucity of information in the literature regarding its biological behavior, clinical outcome, and molecular profile. The most commonly reported cases include components of pheochromocytoma and ganglioneuroma [1]. However, there are only few reports of tumors with components of pheochromocytoma and stroma-poor neuroblastoma (Table 1) [2-7]. We report two distinct cases of composite tumors of the adrenal gland consisting of pheochromocytoma and neuroblastoma.

Electronic supplementary material The online version of this article (https://doi.org/10.1007/s00428-017-2225-9) contains supplementary material, which is available to authorized users.

Peter Pytel

peter.pytel@uchospitals.edu

1 Department of Pathology, University of Chicago, 5841 S. Maryland Ave, Chicago, IL, USA

2 Department of Pediatrics, University of Chicago, 5841 S. Maryland Ave, Chicago, IL, USA

\section{Methods}

Purified DNA was analyzed using the OncoScan ${ }^{\mathrm{TM}}$ Affymetrix microarray platform following the manufacturer's instructions (Affymetrix Inc., Santa Clara, CA). The copy number and genotype data were analyzed using the GeneChip workstation with Affymetrix Molecular Diagnostics Software. OSCHP files were analyzed using Nexus Express Software, Biodiscovery v3.1. Genome build hg19 (Feb 2009) was used for probe locations and data interpretation.

\section{Case report}

\section{Case 1}

A 57-year-old male, who was initially diagnosed with neurofibromatosis type 1 (NF1) after exhibiting facial neurofibromas at age 20, presented with hematochezia. Workup, including CT and MRI, revealed an incidental $3.6 \mathrm{~cm}$ enhancing mass in the left adrenal gland (Fig. 1). A 24-h urine catecholamine collection was obtained which showed an elevated dopamine level of $1015 \mu \mathrm{g} / 24 \mathrm{~h}$ (reference range $52-480 \mu \mathrm{g}$ / $24 \mathrm{~h}$ ), and blood work revealed a plasma normetanephrine level of $2.53 \mathrm{nmol} / \mathrm{L}$ (reference range $0-0.89 \mathrm{nmol} / \mathrm{L}$ ). The patient denied headaches, elevated blood pressure, diaphoresis, shortness of breath, and tachycardia.

He underwent a left adrenalectomy. Grossly, the tumor formed a white to yellow, beige circumscribed mass with patchy hemorrhage. No distinct areas or nodules were appreciated on the gross exam (Fig. 1b). Histologic sections showed an intimate admixture of two distinct components (Fig. 1c-h). The first component exhibited features of a pheochromocytoma with nests of epithelioid to spindled cells. The periphery of the nests contained S100 and SOX10 positive sustentacular 


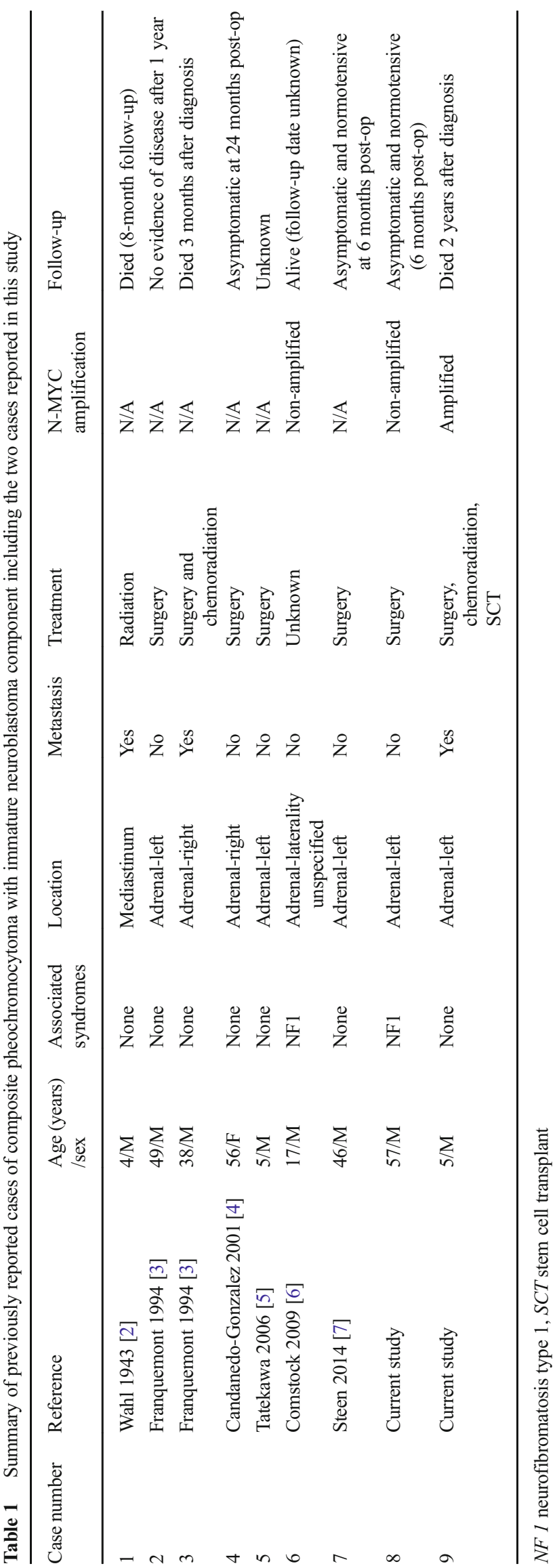

cells. The second component contained fine fibrillary neuropil-type stroma and cells that varied from small neuroblastic to focal ganglion cells. Both components stained for PGP9.5, synaptophysin, and chromogranin but with variable intensities: the neuroblastic component was strongly and diffusely positive for PGP9.5 and only exhibited weak labeling for chromogranin, while the reverse was true for the pheochromocytoma component. Overall, the pheochromocytoma component constituted $60 \%$ of the tumor while the neuroblastic component constituted $40 \%$.

Tissue from each component was dissected from unstained slides matched to a serial hematoxylin and eosin (H\&E) stained section. Whole genome SNP arrays were performed to assess genome wide copy number aberrations (CNAs) and copy neutral regions of loss of heterozygosity ( $\mathrm{LOH})$. Identical gains and losses of the following regions were identified in both tumor components (supplement 1): del(1p), del(4p), dup(4q), del(5q), $\operatorname{del}(6 q), \operatorname{del}(9 p), \operatorname{del}(17 p)$, and trisomy 18 .

Six months post-operatively, the patient showed no evidence of recurrence.

\section{Case 2}

A 5-year-old previously healthy male presented with abdominal pain. An X-ray demonstrated calcifications in the left hemiabdomen extending from the left renal fossa laterally. This was associated with permeative lytic lesions involving the proximal femora and right ischium. He underwent a biopsy of an adrenal mass as well as bilateral bone marrow biopsies. The bone marrow biopsies were positive for involvement by neuroblastoma, and the biopsy of the adrenal mass showed features of a neuroblastic tumor with focal areas of cells in a nested arrangement. At central review, the tumor was classified as a "composite pheochromocytoma" in accordance with the current terminology used in the World Health Organization tumor classification guidelines [8]. Biologic studies were positive for $M Y C N$ amplification. After high-risk neuroblastoma induction therapy, a tumor resection was performed. The patient was then treated with high-risk therapy and a stem cell transplant followed by radiation and isotretinoin. Two years after the initial therapy, the patient developed treatment-refractory metastatic disease and died.

Grossly, the tumor showed a homogeneous surface without distinct nodules. Histologic sections of the resected adrenal tumor revealed similar features as those observed in the pretreatment biopsy (Fig. 2). Some areas exhibited features of neuroblastoma, including immature neuropil-type stroma and immature neuroblastic cells with isolated cells showing focal ganglion cell differentiation. Other areas contained epithelioid cells with relatively abundant cytoplasm in a nested arrangement. In these latter areas, S100 staining highlighted the presence of delicate spindled sustentacular cells around the tumor nests.

In the post-treatment resection specimen of the adrenal gland, approximately $10 \%$ of the specimen was composed of necrotic 
Fig. 1 Patient 1 was a 57-yearold male who was incidentally discovered to have a left adrenal mass lesion on a CT scan performed for hematuria (a). On cross section, the tumor consisted of a demarcated lesion arising within the adrenal gland (b) (size bar $1 \mathrm{~cm}) . H \& E$ images show a biphasic lesion (c) with nested areas of pheochromocytoma (d) that includes S100 positive sustentacular cells (e). Other areas show neuropil-type stroma with immature small neuroblastic cells and rare ganglion cells $(\mathbf{f})$.

PGP9.5 and chromogranin corresponding to the same area seen in panel $\mathrm{C}$ show distinct labeling in the two components. The neuroblastoma component is more strongly positive for PGP9.5 (g) while chromogranin (CMG) expression is largely restricted to the pheochromocytoma component of the tumor (h)
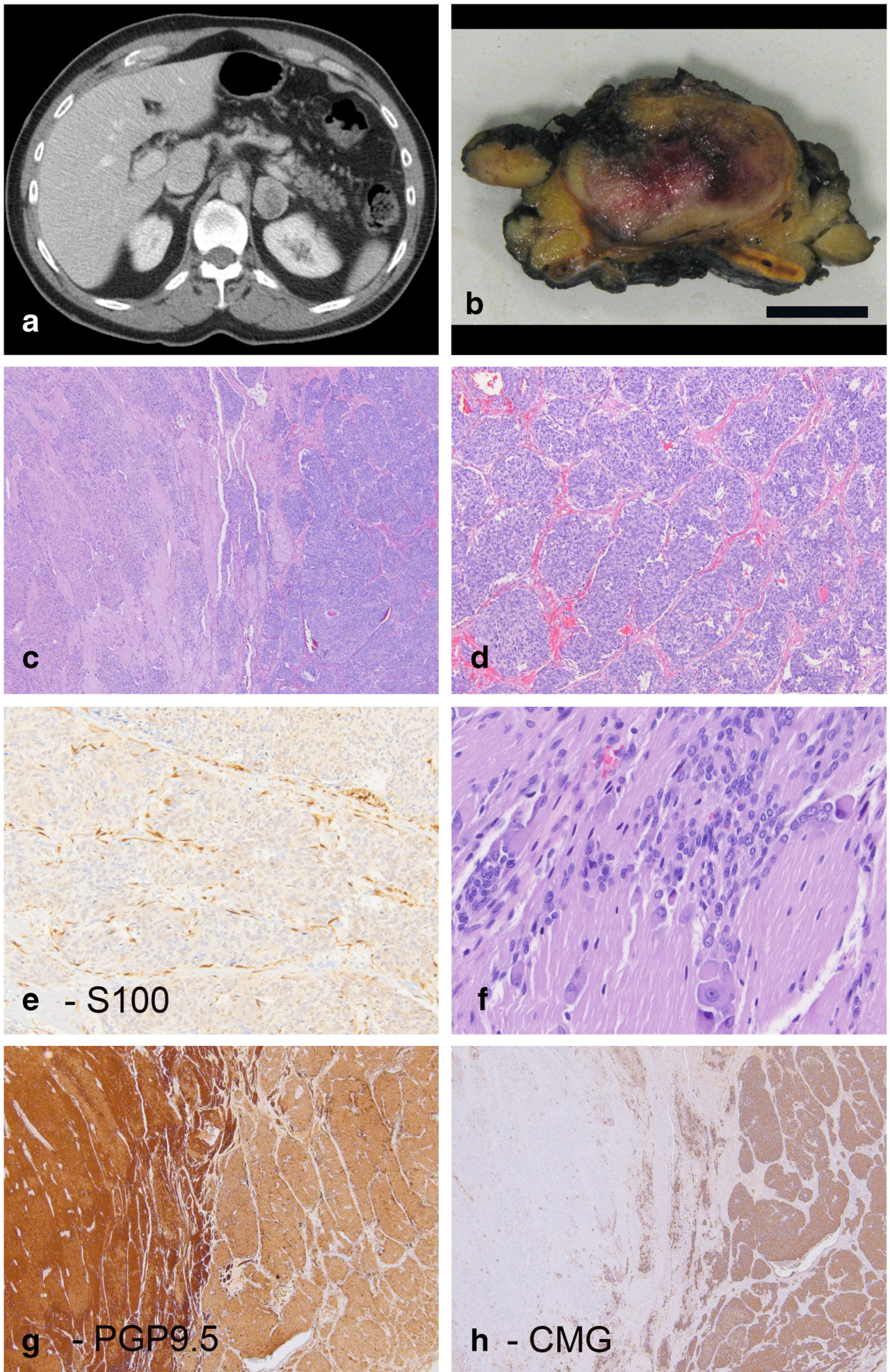

tumor. Both the neuroblastoma and pheochromocytoma components were present in multiple tissue blocks. The neuroblastic component comprised $70 \%$ of the tumor, and the pheochromocytoma component comprised the remaining $20 \%$. Whole genome SNP arrays were attempted in this case also but failed to yield diagnostic results.

\section{Discussion}

Tumors with morphologic features of pheochromocytoma and stroma-poor neuroblastoma in the same lesion are rare and are commonly referred to as "composite pheochromocytoma." Table 1 summarizes the clinical features of published cases 
Fig. 2 Patient 2 was a 5-year-old boy who presented with an adrenal lesion that contained two intimately admixed histomorphologic components. Some areas (a, b) show typical neuroblastoma with focal rosettelike arrangement of immature cells and focal neuropil stroma. Other areas have a distinctly nested arrangement of cells with more abundant cytoplasm $(\mathbf{c}, \mathbf{d})$ and distinct peripheral staining for S100 in a pattern seen with sustentacular cells (e).

Synaptophysin is positive in these latter areas (f)
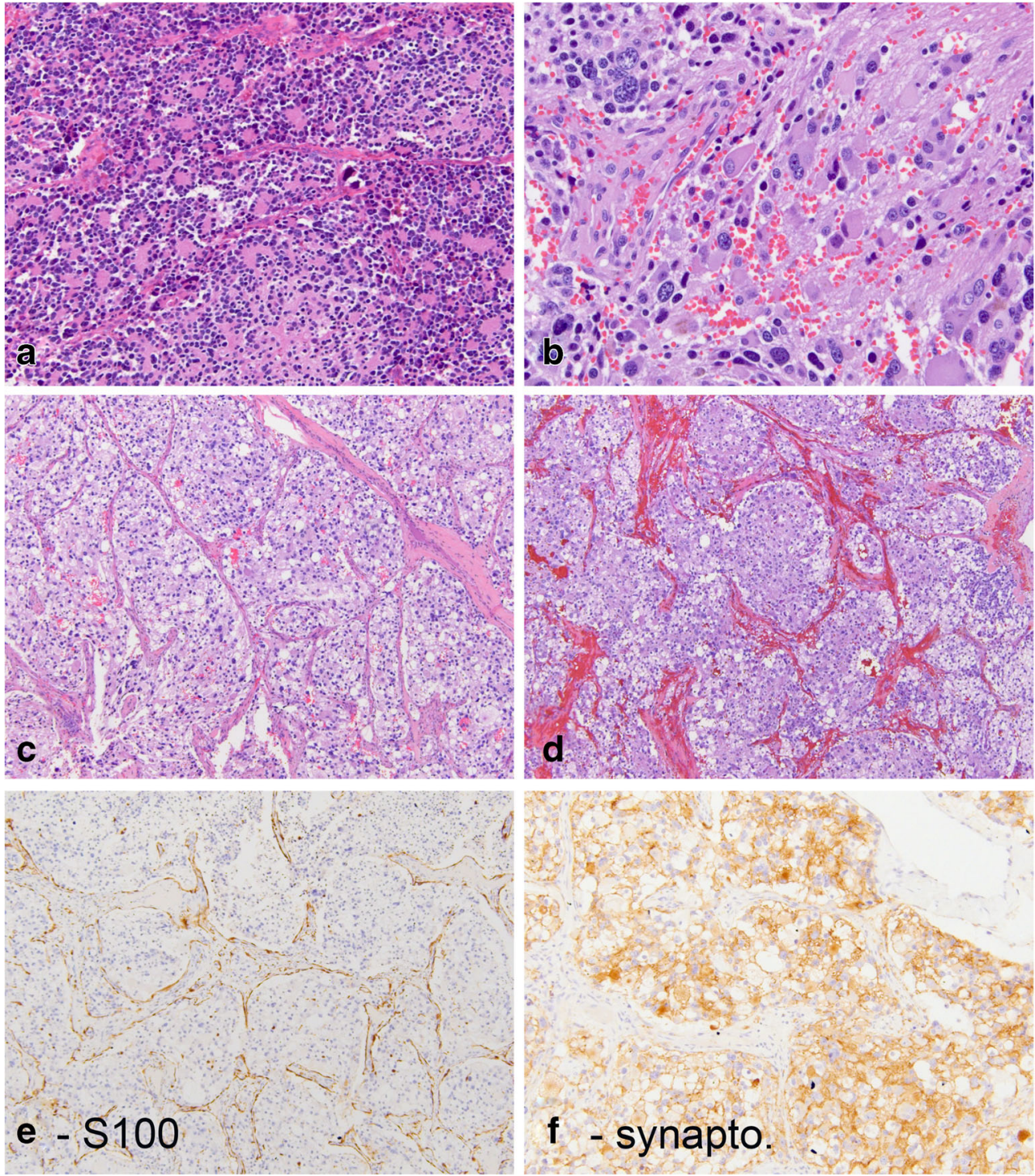

[2-7]. We report two additional cases for which we provide further molecular characterization. Morphologically, both cases share a biphasic appearance with areas of immature stroma-poor neuroblastoma and areas of pheochromocytoma comprised of cells in a nested arrangement outlined by sustentacular cells.

In the first case, SNP microarray results suggest that the two components are clonal since they share the same pattern of chromosomal gains and losses. Furthermore, these gains and losses are largely in concordance with prior published reports for pheochromocytoma [9-11]. The SNP microarray primarily captures large chromosomal changes and is unable to detect mutations, genomic rearrangements, or epigenetic changes. The morphologic difference between the two tumor components may therefore still be associated with and reflective of molecular changes that are not detected by this platform.

Despite the unusual morphologic findings, this first case of an adult with NF1 and an incidentally discovered indolent lesion bears all the clinical features of a pheochromocytoma. This is in contrast to the second case of a young child with a $M Y C N$-amplified tumor that was associated with diffuse bone marrow involvement at presentation. His clinical course was characteristic of high-risk neuroblastoma: he initially responded to high-risk neuroblastoma treatment but subsequently developed relapsed disease that was refractory to treatment, eventually leading to the patient's demise.

A review of the previously published cases of composite tumors with neuroblastic and pheochromocytoma components shows that these cases largely fall into two groups that recapitulate the characteristics of the two reported cases. As shown in Table 1, cases 2, 4, 6, and 7 are adult patients or patients with $\mathrm{NF} 1$, similar to the first case we are reporting. In contrast, case 1 in Table 1 , is a 4 -year-old with rapidly fatal disease, comparable to our second case. No follow-up information is provided for case 5 . Case 3 represents an outlier, since this 38-year-old patient died 
with widely metastatic disease within 3 months of diagnosis. With the exception of the case reported by Comstock et al. which demonstrated no N-MYC gene amplification in the tumor of their NF1 patient [6], other studies did not investigate this important prognostic factor $[2-5,7]$.

The term "composite neuroblastoma" or "composite tumor" has been applied in the context of neuroblastic tumors to describe those rare cases that appear comprised of morphologically distinct clones of neuroblastoma [12-14] while the term "composite pheochromocytoma" has been adopted as a descriptor for tumors exhibiting features of neuroblastoma and pheochromocytoma as illustrated by the two cases reported here. Nevertheless, the term "composite pheochromocytoma" has largely been used in a nondiscriminatory way, regardless of the underlying biology and clinical setting and may, therefore, be misleading for treating physicians. A terminology based on the biology and clinical setting of the tumor is likely to be less ambiguous. Our first case may best be described as "pheochromocytoma with divergent components of neuroblastoma differentiation" while the second case would more accurately be described as "neuroblastoma with divergent components of pheochromocytoma differentiation." Divergent differentiation is observed in various tumors including dedifferentiated liposarcoma and malignant peripheral nerve sheath tumors. One can speculate on the implications of this phenomenon for cell fate, but ultimately this question is not resolved [15]. However, the distinction between neuroblastoma and pheochromocytoma is clinically important because patients with high-risk neuroblastoma require multimodal therapy while those with pheochromocytomas are often cured with surgical resection alone.

Funding The authors did not receive any research funding to support the work that led to this case report.

Compliance with ethical standards This manuscript is a report of two cases with a review of the literature. Research work with human and animal subjects was not conducted in preparation of this manuscript.

Conflict of interest The authors declare that they have no conflict of interest.

Open Access This article is distributed under the terms of the Creative Commons Attribution 4.0 International License (http:// creativecommons.org/licenses/by/4.0/), which permits unrestricted use, distribution, and reproduction in any medium, provided you give appropriate credit to the original author(s) and the source, provide a link to the Creative Commons license, and indicate if changes were made.

\section{References}

1. Khan AN, Solomon SS, Childress RD (2010) Composite pheochromocytoma-ganglioneuroma: a rare experiment of nature. Endocr Pract 16(2):291-299. https://doi.org/10.4158/EP09205.RA
2. Wahl HR, Robinson D (1943) Neuroblastoma of mediastinum with pheochromoblastous elements. Arch Path 35:571-578

3. Franquemont DW, Mills SE, Lack EE (1994) Immunohistochemical detection of neuroblastomatous foci in composite adrenal pheochromocytoma-neuroblastoma. Am J Clin Pathol 102(2):163-170

4. Candanedo-Gonzalez FA, Alvarado-Cabrero I, GamboaDominguez A, Cerbulo-Vazquez A, Lopez-Romero R, Bornstein-Quevedo L, Salcedo-Vargas M (2001) Sporadic type composite pheochromocytoma with neuroblastoma: clinicomorphologic, DNA content and ret gene analysis. Endocr Pathol 12(3):343-350

5. Tatekawa Y, Muraji T, Nishijima E, Yoshida M, Tsugawa C (2006) Composite pheochromocytoma associated with adrenal neuroblastoma in an infant: a case report. J Pediatr Surg 41(2):443-445. https://doi.org/10.1016/j.jpedsurg.2005.11.024

6. Comstock JM, Willmore-Payne C, Holden JA, Coffin CM (2009) Composite pheochromocytoma: a clinicopathologic and molecular comparison with ordinary pheochromocytoma and neuroblastoma. Am J Clin Pathol 132(1):69-73. https://doi.org/10.1309/ AJCPN76VTIGWPOAG

7. Steen O, Fernando J, Ramsay J, Prebtani AP (2014) An unusual case of a composite pheochromocytoma with neuroblastoma. J Endocrinol Metab 4(1):39-46. 10.14740/jem211w

8. Lam AK (2017) Update on adrenal tumours in 2017 World Health Organization (WHO) of endocrine tumours. Endocr Pathol. https:// doi.org/10.1007/s12022-017-9484-5

9. Edstrom E, Mahlamaki E, Nord B, Kjellman M, Karhu R, Hoog A, Goncharov N, Teh BT, Backdahl M, Larsson C (2000) Comparative genomic hybridization reveals frequent losses of chromosomes $1 \mathrm{p}$ and $3 \mathrm{q}$ in pheochromocytomas and abdominal paragangliomas, suggesting a common genetic etiology. Am J Pathol 156(2):651-659. https://doi.org/10.1016/S0002-9440(10) 64769-4

10. Lemeta S, Salmenkivi K, Pylkkanen L, Sainio M, Saarikoski ST, Arola J, Heikkila P, Haglund C, Husgafvel-Pursiainen K, Bohling T (2006) Frequent loss of heterozygosity at $6 \mathrm{q}$ in pheochromocytoma. Hum Pathol 37(6):749-754. https://doi.org/10.1016/j.humpath. 2006.02.002

11. Petri BJ, Speel EJ, Korpershoek E, Claessen SM, van Nederveen FH, Giesen V, Dannenberg H, van der Harst E, Dinjens WN, de Krijger RR (2008) Frequent loss of 17p, but no p53 mutations or protein overexpression in benign and malignant pheochromocytomas. Mod Pathol 21(4):407-413. https://doi.org/10.1038/ modpathol.3801013

12. Bishop MW, Yin H, Shimada H, Towbin AJ, Miethke A, Weiss B (2014) Management of stage 4S composite neuroblastoma with a MYCN-amplified nodule. J Pediatr Hematol Oncol 36(1):e31-e35. https://doi.org/10.1097/MPH.0b013e3182847376

13. Sano H, Gonzalez-Gomez I, Wu SQ, Armenian SH, Jubran RF, Shimada H (2007) A case of composite neuroblastoma composed of histologically and biologically distinct clones. Pediatr Dev Pathol 10(3):229-232. https://doi.org/10.2350/0606-0117.1

14. Shimada H, Ambros IM, Dehner LP, Hata J, Joshi VV, Roald B (1999) Terminology and morphologic criteria of neuroblastic tumors: recommendations by the international neuroblastoma pathology committee. Cancer 86(2):349-363

15. Shankar GM, Chen L, Kim AH, Ross GL, Folkerth RD, Friedlander RM (2010) Composite ganglioneuromaparaganglioma of the filum terminale. J Neurosurg Spine 12(6): 709-713. https://doi.org/10.3171/2009.12.SPINE09482 